\title{
Is there difference of Streptococcus mutans count and adherence on amalgam and resin occlusal restorations? A blind clinical study
}

\author{
Patricio Agustin Vildósola Grez ${ }^{1}$, Eduardo Fernandez Godoy ${ }^{1}$, Patricia Palma Fluxá ${ }^{3}$, \\ Gustavo Adolfo Moncada Cortés ${ }^{4}$, Jose Roberto Cury Saad ${ }^{2}$, Javier Martin Casielles ${ }^{1}$ \\ ${ }^{1}$ Universidad de Chile, Dental School, Department of Restorative Dentistry, Santiago, Chile \\ ${ }^{2}$ Universidade Estadual Paulista - UNESP, Araraquara Dental School, Department of Restorative Dentistry, Araraquara, SP, Brazil \\ ${ }^{3}$ Universidad de Chile, Dental School, Department Medicine and Oral Pathology, Area of Microbiology, Santiago, Chile \\ ${ }^{4}$ Universidad Mayor, Dental School, Area of Cariology, Santiago, Chile
}

\begin{abstract}
Aim: To compare the number of colony forming units (CFU) and agar adherence of $S$. mutans on amalgam (AM) and resin composite (RC) occlusal restorations. Sixty-five healthy patients older than 18 years with high caries risk who had at least one occlusal AM and RC restorations ( $n=130)$ were selected. Methods: The restorations were evaluated according to the alpha Ryge criteria (Cohen-Kappa 0.8). For each patient, a biofilm sample was taken using an impression tray technique with previously loaded with solid trypticase yeast extract cysteine sucrose with bacitracin agar placed over the AM restorations and RC restorations in the same patients. The tray was placed inside an oven at $37^{\circ} \mathrm{C}$ for $48 \mathrm{~h}$, and the $\mathrm{S}$. mutans count was then performed. Data were analyzed with the test Wilcoxon with a 95\% confidence level. Results: RC restorations had statistically significant higher number of CFU of $S$. mutans than AM restorations $(p<0.05)$. Conclusions: In adult patients with high caries risk, RC occlusal surfaces showed greater agar adherence of $S$. mutans count than AM restorations.
\end{abstract}

Keywords: Streptococcus mutans; composite resins; dental amalgam.

\section{Introduction}

Dental caries represents one of the most common global diseases. Although most industrialized countries have lowered their caries rates, it cannot be completely eradicated. Therefore, new treatments are needed, as caries continues to be a significant burden in terms of both morbidity and economics ${ }^{1}$.

Among the factors involved in the complex process of caries disease are oral

Received for publication: November 18, 2014 Accepted: January 29, 2015

Correspondence to: Patricio Agustin Vildósola Grez Department of Restorative Dentistry Universidad de Chile Dental School Santiago, Chile

Phone: +56 $0229781742 \quad$ Fax +56 0229781742 E-mail: patovildo@gmail.com bacteria, which are immersed in a cariogenic biofilm in a balanced oral environment ${ }^{2}$. This microbiological balance can be modified by a higher intake of carbohydrates, thus increasing the acidogenic bacterial population that is responsible for the demineralization and destruction of tooth surfaces leading to carious lesions ${ }^{3}$. Of the species present in cariogenic biofilm, Streptococcus mutans is considered one of the main etiological agents of caries disease, particularly in the case of early disease ${ }^{3}$.

A biofilm is formed immediately on all exposed surfaces in the oral environment ${ }^{4}$ making the biological interaction between restorative materials and 
the microorganisms. Indeed, different surface restoration properties could directly influence the level of bacterial adhesion and aggregation ${ }^{5}$. This suggests that restorative materials should be selected according to a patient's caries risk, which could plays a significant role in the longevity of restorations ${ }^{6-7}$.

For many years, amalgam (AM) has been the main restorative material in the posterior zone; however, resin composite (RC) restorations are also a popular filling material because of their good esthetics and adhesion properties ${ }^{8}$. Nevertheless, despite these properties secondary caries is the major reason for the replacement of RC restorations ${ }^{9-10}$, as they have higher incidence of secondary caries than AM restorations ${ }^{11}$.

Previous investigations have reported that RC restorations promote bacterial growth on their surface ${ }^{11-12}$, suggesting that material-specific factors may be involved ${ }^{13}$. In other way previous studies have reported that AM inhibits bacterial adhesion because of its ability to release silver ${ }^{14}$ however, there is insufficient evidence that the release of these elements has a purely antibacterial effect ${ }^{15}$.

For this reason, it will be interesting to determine the levels of $S$. mutans colonizing the surfaces of AM and RC restorations in the oral environment.

The objective of this study was to compare the colonization levels by assessing the colony forming unit (CFU) count and the agar adherence of $S$. mutans on occlusal surfaces in $\mathrm{AM}$ and $\mathrm{RC}$ restorations. The alternative hypothesis is that there are differences between the $S$. mutans CFU count between AM and RC restorations.

\section{Material and methods}

This research was approved as a Dental School project at the Universidad de Chile, number PRI-ODO 11-02, by its Ethics Committee. Each patient was informed in detail about the research and signed a written consent. Because these patients had a high cariogenic risk, they received preventive measures and a treatment plan according to their risk after study sampling

The size of the sample was calculated with analyses a priori using the statistical program $\mathrm{G}^{*}$ Power $\odot$, Version 3.1.3 (Enrich-Heine, Universität Düsseldorf, Düsseldorf, Germany), with confidence levels of $95 \%(\alpha=0.05)$ and a statistical power of $80 \%$. The size effect was medium (0.5). The analysis indicated that at least 65 patients were required to achieve significant results. The statistical unit was the patient.

A total of 584 patients were examined at the Operative Dentistry Clinic of the Universidad de Chile Dental School, and 65 of these and restorations were randomly selected for inclusion in the study (total sample size of 130, with 2 samples from each patient, $\mathrm{n}=65$ ) using NCSS PASS 2008, v08.0.15 (NCSS Statistical Software Co., Kaysville, USA).

The following inclusion and exclusion criteria were established:

Inclusion Criteria: Patients between 18 and 45 years with homonymous amalgam (Original D, Wyckle Research In., Carson City, NV, USA) and composite restorations (Filtek Supreme, 3M ESPE, St. Paul, MN, USA), restorations must have an alpha value in five parameters, according to the United State Public Health Service (USPHS) clinical criteria for the evaluation of restorations ${ }^{16}$ (Table 1). A calibrated clinician evaluated these values (Cohen Kappa 0.8). Dental restorations placed within a 3-year period in the Operative Clinic of the Universidad de Chile Dental School, maxillary and mandibular occlusal posterior restorations were included when they did not exceed one-third of the intercuspal distance, patients with high caries risk according to Cariogram 2.01 software (Mälmo University, Mälmo, Sweden).

Exclusion Criteria: Patients undergoing treatment with a mouthwash and/or antimicrobial gel, taking antibiotics at the time of the study or in the last 3 months, with fixed or removable prosthetics, fixed or removable orthodontics and any other acrylic device, taking immunosuppressive drugs,

Table 1. Ryge Criteria

\begin{tabular}{|c|c|c|c|}
\hline $\begin{array}{l}\text { Clinical } \\
\text { Characteristic }\end{array}$ & Alpha & Bravo & Charlie \\
\hline $\begin{array}{l}\text { Marginal } \\
\text { Adaptation }\end{array}$ & $\begin{array}{l}\text { Explorer does not catch or has one way catch } \\
\text { when drawn across the restoration/tooth interface }\end{array}$ & $\begin{array}{l}\text { Explorer falls into crevice when drawn } \\
\text { across the restoration/tooth interface }\end{array}$ & $\begin{array}{l}\text { Dentin or base is exposed along the } \\
\text { margin }\end{array}$ \\
\hline $\begin{array}{l}\text { Anatomic } \\
\text { Form }\end{array}$ & $\begin{array}{l}\text { The general contour of the restorations follows the } \\
\text { contour of the tooth }\end{array}$ & $\begin{array}{l}\text { The general contour of the restoration } \\
\text { does not follow the contour of the tooth }\end{array}$ & The restoration has an overhang \\
\hline $\begin{array}{l}\text { Surface } \\
\text { Roughness }\end{array}$ & $\begin{array}{l}\text { The surface of the restoration does not have any } \\
\text { surface defects }\end{array}$ & $\begin{array}{l}\text { The surface of the restoration has } \\
\text { minimal surface defects }\end{array}$ & $\begin{array}{l}\text { The surface of the restoration has severe } \\
\text { surface defects }\end{array}$ \\
\hline $\begin{array}{l}\text { Secondary } \\
\text { Caries }\end{array}$ & There is no clinical diagnosis of caries & N/A & $\begin{array}{c}\text { Clinical diagnosis of caries at restoration } \\
\text { margin }\end{array}$ \\
\hline $\begin{array}{l}\text { Luster of } \\
\text { Restoration }\end{array}$ & $\begin{array}{l}\text { The restoration surface is shiny and has an } \\
\text { enamel-like, translucent surface }\end{array}$ & $\begin{array}{l}\text { The restoration surface is dull and } \\
\text { somewhat opaque }\end{array}$ & $\begin{array}{l}\text { The restoration surface is distinctly dull } \\
\text { and opaque and is esthetically } \\
\text { displeasing }\end{array}$ \\
\hline
\end{tabular}


such as corticosteroids, classified as ASA III according to the American Society of Anesthesiologists, who chew gum at least four days per week, with a physical disability that precludes them from being responsible for their own hygiene. The patient selection procedures were designed by two operators.

Microbiological sample: Prior to sampling the biofilm, trays were prepared to print the biofilm over the restorations ${ }^{17}$. For this application, we used disposable fluoride gel application trays (Deepak Products Inc., Miami, USA), each of which was sterilized in a biosafety hood (Esco Technologies Inc., Harboro, USA) under ultraviolet light for 30 minutes. Each tray was then charged with $7.5 \mathrm{ml}$ of TYCSB agar (Casein, yeast extract, L-cysteine, sucrose, bacitracin) (Difco Laboratories Inc., Detroit, MI, USA), a selective medium for $S$. mutans ${ }^{18}$. Subsequently, to individualize the sample collection technique, the trays were cut to fit no more than 3 teeth. Immediately after this, the trays were placed in sterile petri plates and stored in sealed plastic bags in the refrigerator for storage. Before use, the trays were placed in an incubator/stove (ZDP-A2080, LabTech Co., Namyangiu, Korea) for $24 \mathrm{~h}$ at $37{ }^{\circ} \mathrm{C}$ as a quality control measure. The third and fourth operators performed the sampling, which was conducted between 11:00-13:00 to allow for biofilm reorganization following morning brushing. The sampling was performed by gently pressing the tray for $20 \mathrm{~s}$ over the RC restoration followed by the homologous AM restoration for each patient and then each tray was assigned a number by the third operator into the database. After the sample trays were stored in sterile Petri plates, they were transported at $4{ }^{\circ} \mathrm{C}$ and then incubated at $37{ }^{\circ} \mathrm{C}$ in a microaerophilic (jar candle $\mathrm{CO}_{2} 10 \%$ ) for $48 \mathrm{~h}$. Count of $S$. mutans: This procedure was performed by the fourth operator who was blinded to which tray was used to print the AM or $\mathrm{RC}$ restorations. The operator was calibrated for the $S$. mutans count before this analysis (Cohen Kappa >0.8). After $48 \mathrm{~h}$ of incubation, macroscopic counts of colonies compatible with $S$. mutans morphology were performed, and the agar adherence of the colonies was observed under an optical microscope with a light source (Schott KL 1500, Carl Zeiss Microscopy, Thornwood, USA). Later, Gram staining was performed to determine the micromorphology of the colonies. The $S$. mutans count was expressed in colony forming units (CFU) of $S$. mutans from the plates and trays with the TYCSB agar. Selected colonies that were compatible with $S$. mutans adhesion and morphological characteristics were suspended in Todd-Hewitt broth (Difco Laboratories Inc., Detroit, MI, USA) and incubated at $37{ }^{\circ} \mathrm{C}$ for $48 \mathrm{~h}$. The colonies were then subjected to biochemical tests to identify the species of Mutans streptococci and to distinguish $S$. mutans from $S$. sobrinus. The biochemical tests included the raffinose fermentation test, the melibiose fermentation and esculin hydrolysis tests. A positive result for all three tests indicated the presence of $S$. mutans $^{19}$. After $48 \mathrm{~h}$, each incubated broth sample was centrifuged (BD Sero-Fuge 2001, Clay-Adams Becton Dickinson and Co., Sparks, MD, USA) for $5 \mathrm{~min}$ at approximately $1500 \mathrm{rpm}$ to obtain a pellet. The pellet was resuspended in $450 \mu \mathrm{L}$ of phosphate buffer $(\mathrm{pH}$ 7.2) to approximate a McFarland 5 standard. Then, $100 \mu \mathrm{L}$ of this suspension was inoculated in each biochemical test such as esculin (Brain Heart infusion, 1\% esculin. Difco Laboratories Inc.), raffinose and melibiose (thioglycolate without dextrose and no indicator, $1 \%$ of raffinose, $1 \%$ of melibiose (Difco, Laboratories Inc.) and incubated for $24 \mathrm{~h}$ at $37{ }^{\circ} \mathrm{C}$. Subsequently, two drops of ferric ammonium citrate (SigmaAldrich Co., St. Louis, MI, USA) were added to the melibiose and raffinose broths.

Analysis of results: Statistical analysis was performed by the fifth operator was blinded. The data distribution was assessed using the Kolmogorov-Smirnov test. For the statistical analysis of the variables it used the Wilcoxon test in the Statistical Package for Social Sciences (SPSS) software for Windows, version 15.0 (SPSS Inc., Chicago, USA), with a significance level of $95 \%$.

\section{Results}

Sixty-five patients with mean age of 30 years and 130 restorations were evaluated $(n=130)$. The tests gave positive results for $S$. mutans fermented the raffinose, melibiose (both yellow coloration) and esculin (black coloration). Based on the bacterial isolation from plaque samples collected through the tray technique, isolated colonies were obtained with macroscopic properties and adhesion characteristics that were indicative of $S$. mutans (Figure 1 and 2) AM restorations had a median of $2.00 \mathrm{CFU}$. In contrast, $\mathrm{RC}$ restorations had a median of $3.00 \mathrm{CFU}$ (Graph 1). The median total CFU the both samples in the same patient was 2.5 According to the Kolmogorov-Smirnov test $(p<0.05)$, the distribution was not normal. The Wilcoxon test showed that there were statistically significant differences between the $\mathrm{AM}$ and $\mathrm{RC}$ restorations with $\mathrm{p}<0.05$.

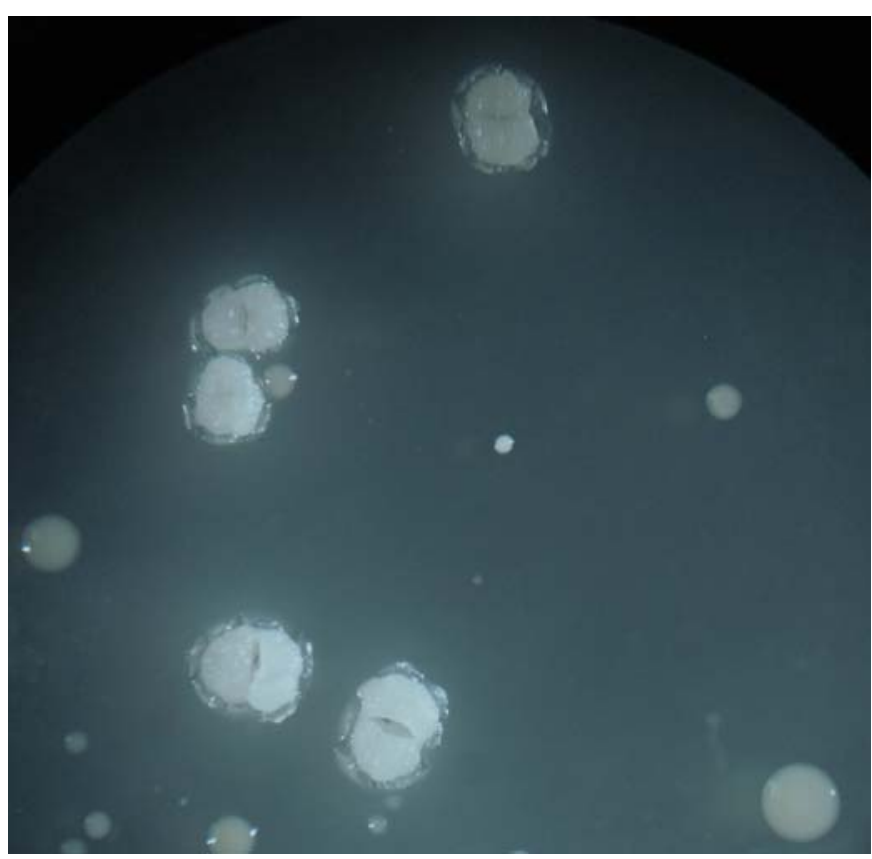

Fig. 1. S. Mutans colonies on TYCSB agar exhibit a whitish, rough surface and crystalline appearance. (Observed under $4 \mathrm{X}$ magnification) 

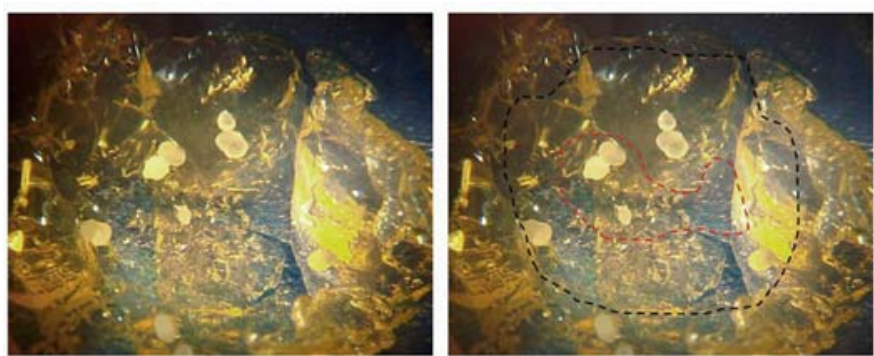

Fig. 2. Bacterial isolation from surface restoration using TR. (A) Colonies of $S$. Mutans adhered to the agar. (B) The red line represents the outline of occlusal surface restoration.

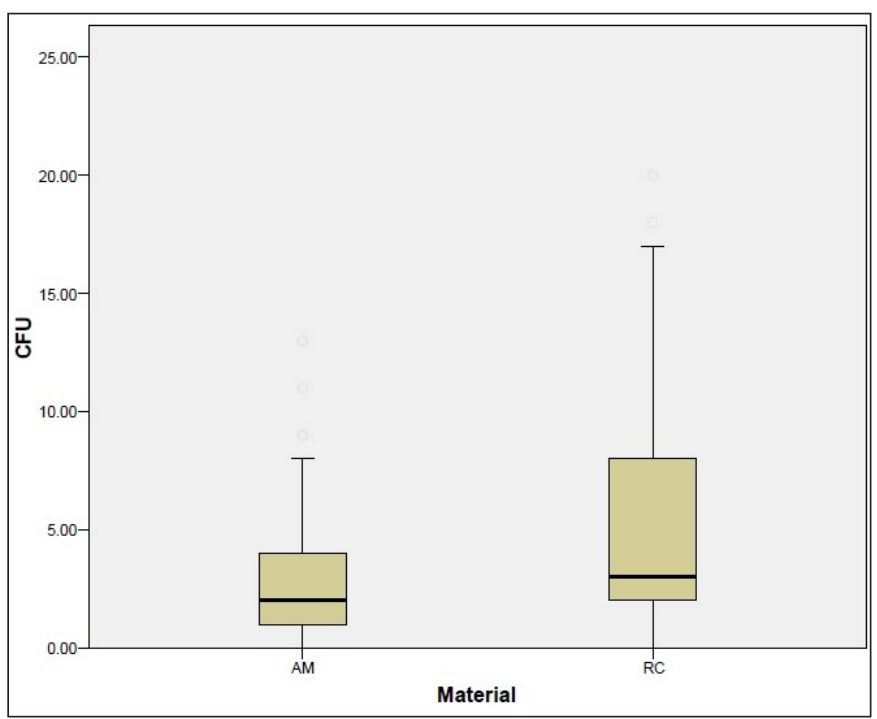

Graph 1. Distribution of $S$. mutans CFU on the AM and RC restorations.

\section{Discussion}

When the $S$. mutans CFU of collected from AM and RC restorations using the tray technique were compared, a significantly greater number was found in the RC group $(\mathrm{p}<0.05)$. The results of this study thus confirm our original hypothesis; the differences between the sample groups observed here coincide with similar clinical and in vitro studies of $S$. mutans on restorations, in which higher levels were generally found on $\mathrm{RC}$ restorations than on $\mathrm{AM}$ restorations ${ }^{11,20}$.

The AM and RC samples were taken from the same patient to ensure that the biofilm samples deposited on the restorations were from the same oral ecosystem with the same ecological characteristics. Furthermore, all samples were taken from restorations that were classified as alpha according to the modified Ryge criteria with the same longevity ( 3 years).

This means that the restorations were studied under similar conditions to homogenize the samples, which could indicate that the differences in the CFU of $S$. mutans on the restorations are mainly due to the characteristics of each material, rather than to ecosystem changes or differences in status, such as a retentive restoration sector that would favor the accumulation of plaque. This is relevant because it has been describe that the characteristics of restorative materials could influence the level of subsequent bacterial growth ${ }^{15}$.

This finding has been associated with the physical and chemical characteristics of the restorative materials ${ }^{20}$. Physical properties, such as the porosity of the restorative material, may be important at the nanometer scale ${ }^{21}$. Indeed, preliminary studies have shown differences in the adhesion of biofilm to resins of different surface roughness ${ }^{22}$. This could help explaining the increase of bacterial $\mathrm{CFU}$ on the $\mathrm{RC}$ restorations, as these have a greater roughness at the nanometer scale than do polished AM restorations with similar macroscopic characteristics, as assessed by the Ryge criteria. Furthermore, for these changes to occur on the surfaces of the restorations they must be exposed to the oral environment for a certain amount of time since an in situ study with short-term evaluation period had contradictory results to this study ${ }^{23}$.

Chemical surface properties have proven to be a relevant factor in bacterial colonization and adherence. The main influence is the chemical composition of the restoration's surface, which may have components that benefit the microorganisms ${ }^{20}$. In this case, AM restorations may have certain adhesion inhibition qualities, as they release antibacterial elements such as silver ${ }^{14}$. However, this alone is not sufficient to clearly show that AM releases antibacterial elements ${ }^{15}$.

Furthermore, RC is not believed to possess any antibacterial activity and is considered to actually promote bacterial colonization and growth, as its co-monomers can actually stimulate cariogenic bacterial species ${ }^{12,24}$. There are several studies that describe and explain the stimulation of bacterial growth on resin composites due to monomer degradation, specifically $S$. mutans. This explains why the action of the esterase enzymes in human saliva causes the degradation of triethylene glycol dimethacrylate (TEGDMA) in triethylene glycol (TEG), which is released in the oral environment and affects the expression of $S$. mutans glucosyltransferase and thus increases the bacterial synthesis of glucan ${ }^{25}$. However, there is not clear evidence for this mechanism because the degradation products are found in monomer-dependent concentrations and there is a lack of knowledge about what happens in vivo. In the oral cavity, this process might be directly affected by the biofilm, which is highly complex and heterogeneous, and there might be mechanisms that work to regulate bacterial cell functions in response to the oral environment ${ }^{26}$. RC degradation is especially important in this context because it increases the surface roughness of the restoration, thereby promoting adhesion and stimulating the growth of $S$. mutans ${ }^{24}$. Additionally, RC restorations may have a greater level of microfiltration than AM restorations ${ }^{26}$, which might also help explain the shorter life of RC restorations. Several studies have described this finding in regards to the higher failure rate of $\mathrm{RC}$ restorations due to secondary caries, especially in high caries risk patients ${ }^{6,13}$.

Opdam $^{6}$ has reported that the caries risk of a patient plays a significant role in the longevity of a restoration, for example a patient with high caries risk presumably has an oral environment that will negatively affect the restorations. As shown in our study, it might be necessary to assess the 
selection of restorative materials in terms of their longevity in a high caries risk environment. However, in patients with low caries risk, the $\mathrm{AM}$ and $\mathrm{RC}$ restorations have similar longevity, with both being in reportedly good condition 12 years after restoration placement ${ }^{7}$.

Within the limitations of the study is that currently caries is known to be a highly complex disease that depends not only on $S$. mutans, but also on a complex ecosystem of multiple bacteria in association with other factors within the oral environment ${ }^{2}$. This is the reason why it has been suggested to research others microorganism.

It would also be interesting to follow the development of secondary caries among the patients included in this study and to make an accurate determination of the association between $S$. mutans or other microorganisms and caries risk.

Within the limitations of this study it can be concluded that in adult patients with high caries risk, RC occlusal surfaces showed greater agar adherence of $S$. mutans count than AM restorations. This result suggests that, for these patients, it would be recommendable to indicate AM restorations instead of $\mathrm{RC}$ in the posterior teeth, thus helping reducing the potential risk the secondary caries.

\section{Reference}

1. Marcenes W, Kassebaum NJ, Bernabé E, Flaxman A, Naghavi M, Lopez A, et al. Global burden of oral conditions in 1990-2010: a systematic analysis. J Dent Res. 2013; 92: 592-7.

2. Takahashi N, Nyvad B. The role of bacteria in the caries process: ecological perspectives. J Dent Res. 2011; 90: 294-303.

3. Beighton $\mathrm{D}$. The complex oral microflora of high-risk individuals and groups and its role in the caries process. Community Dent Oral Epidemiol. 2005; 33: 248-55.

4. Moons $P$, Michiels $C W$, Aertsen A. Bacterial interactions in biofilms. Crit Rev Microbiol. 2009; 35: 157-68.

5. Quirynen $\mathrm{M}$. The clinical meaning of the surface roughness and the surface free energy of intra-oral hard substrata on the microbiology of the supraand subgingival plaque: results of in vitro and in vivo experiments. J Dent. 1994; 22(Suppl 1): S13-6.

6. Opdam NJ, Bronkhorst EM, Loomans BA, Huysmans MC. 12-year survival of composite vs. amalgam restorations. J Dent Res. 2010; 89: 1063-7.

7. Simecek JW, Diefenderfer KE, Cohen ME. An evaluation of replacement rates for posterior resin-based composite and amalgam restorations in U.S. Navy and marine corps recruits. J Am Dent Assoc. 2009; 140: 2009; quiz 49.

8. Ferracane JL. Resin composite-state of the art. Dent Mater. 2011; 27: 29-38.

9. Opdam NJ, van de Sande FH, Bronkhorst E, Cenci MS, Bottenberg P, Pallesen U, et al. Longevity of Posterior Composite Restorations: A Systematic Review and Meta-analysis. J Dent Res. 2014; 93: 943-9.

10. Kopperud SE, Tveit AB, Gaarden T, Sandvik L, Espelid I. Longevity of posterior dental restorations and reasons for failure. Eur J Oral Sci. 2012; 120: $539-48$

11. Beyth N, Bahir R, Matalon S, Domb AJ, Weiss El. Streptococcus mutans biofilm changes surface-topography of resin composites. Dent Mater. 2008; 24: $732-6$

12. Leinfelder KF. Do restorations made of amalgam outlast those made of resin-based composite? J Am Dent Assoc. 2000; 131: 1186-7.

13. Bernardo $M$, Luis $H$, Martin MD, Leroux BG, Rue $T$, Leitão J, et al. Survival and reasons for failure of amalgam versus composite posterior restorations placed in a randomized clinical trial. J Am DentAssoc. 2007; 138: $775-83$
14. Orstavik D. Antibacterial properties of and element release from some dental amalgams. Acta Odontol Scand. 1985; 43: 231-9.

15. Busscher HJ, Rinastiti M, Siswomihardjo W, van der Mei HC. Biofilm formation on dental restorative and implant materials. J Dent Res. 2010; 89: 657-65.

16. Ryge G. Clinical criteria. Int Dent J. 1980; 30: 347-58.

17. Vildósola Grez P, Palma Fluxa P, Zuñiga Saavedra P, Fernandez Godoy E, Batista de Oliverira Jr O, Moncada Cortes G. Recovering Streptococcus mutans over restorations by the tray technique: a randomized clinical study. Braz J Oral Sci. 2013; 12: 292-7.

18. Van Palenstein Helderman WH, ljsseldijk M, Huis in 't Veld JH. A selective medium for the two major subgroups of the bacterium Streptococcus mutans isolated from human dental plaque and saliva. Arch Oral Biol. 1983; 28 : 599-603.

19. Coykendall AL. Classification and identification of the viridans streptococci. Clin Microbiol Rev. 1989; 2: 315-28.

20. Auschill TM, Arweiler NB, Brecx M, Reich E, Sculean A, Netuschil L. The effect of dental restorative materials on dental biofilm. Eur J Oral Sci. 2002; 110: 48-53.

21. Mei L, Busscher HJ, van der Mei HC, Ren Y. Influence of surface roughness on streptococcal adhesion forces to composite resins. Dent Mater. 2011; 27: 770-8.

22. Padovani G, Fúcio S, Ambrosano G, Sinhoreti M, Puppin-Rontani R. In situ surface biodegradation of restorative materials. Oper Dent. 2014; 39: $349-60$.

23. van de Sande FH, Opdam NJ, Truin GJ, Bronkhorst EM, de Soet JJ, Cenci MS, et al. The influence of different restorative materials on secondary caries development in situ. J Dent. 2014; 42: 1171-7.

24. Gregson KS, Shih H, Gregory RL. The impact of three strains of oral bacteria on the surface and mechanical properties of a dental resin material. Clin Oral Investig. 2012; 16: 1095-103.

25. Khalichi P, Singh J, Cvitkovitch DG, Santerre JP. The influence of triethylene glycol derived from dental composite resins on the regulation of Streptococcus mutans gene expression. Biomaterials. 2009; 30: 452-9

26. Alptekin T, Ozer F, Unlu N, Cobanoglu N, Blatz MB. In vivo and in vitro evaluations of microleakage around Class I amalgam and composite restorations. Oper Dent. 2010; 35: 641-8. 